\title{
Evaluating natural compounds as potential insecticides against three economically important pests, Bemisia tabaci (Hemiptera: Aleyrodidae), Frankliniella occidentalis (Thysanoptera: Thripidae), and Myzus persicae (Hemiptera: Aphididae), on greenhouse sweet peppers
}

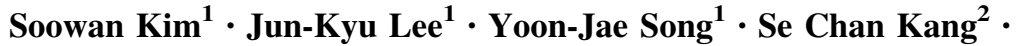 \\ Baeyoung Kim ${ }^{3} \cdot$ I-Jin Choi ${ }^{4} \cdot$ Doo-Hyung Lee ${ }^{1}$ \\ Received: 26 January 2018/ Accepted: 15 March 2018/Published online: 26 March 2018 \\ (C) The Korean Society for Applied Biological Chemistry 2018
}

\begin{abstract}
Sweet pepper (Capsicum annuиm L.) is one of the major export crops in the Republic of Korea. Currently, synthetic insecticides are frequently used to control major greenhouse pests including Bemisia tabaci (Hemiptera: Aleyrodidae), Myzus persicae (Hemiptera: Aphididae), and Frankliniella occidentalis (Thysanoptera: Thripidae) in Korea. However, the repeated use of chemicals has caused insecticide resistance to be developed by pests. Therefore, there is a growing demand to develop biopesticides that have high insecticidal effects but little adverse impacts to crops and nontarget organisms. In this study, three natural compounds were investigated for insecticidal effects against three pests, B. tabaci, M. persicae, and F. occidentalis, and nontarget effects to a pollinator, Bombus terrestris (Hymenoptera: Apidae) in laboratory. The three natural compounds, named JP503, G.sol ${ }^{\circledR}$, and NO40, were an extract from Perilla frutescens var. crispa with phytoncide essential oil from pine tree, a commercialized disinfectant solution, and a type of nitric oxide in aqueous solution. Among these compounds, JP503 showed high and acute insecticidal effects on all of the three pests causing $100 \%$ mortality in $3 \mathrm{~h}$. In addition, this compound resulted in the same level of acute lethality to the pollinator.
\end{abstract}

Doo-Hyung Lee

d1343@gachon.ac.kr

1 Department of Life Sciences, Gachon University, Seongnam-si, Gyeonggi-do, Republic of Korea

2 Department of Oriental Medicine Biotechnology, Kyung Hee University, Yongin-si, Gyeonggi-do, Republic of Korea

3 Phylus Co. Ltd., Danyang-gun, Chungcheongbuk-do, Republic of Korea

4 Department of Agriculture Education, Seoul Metropolitan Agricultural Technology Center, Seoul, Republic of Korea
Moreover, JP503 caused significant leaf damage when applied to sweet pepper plants in greenhouse conditions. The results indicate that the candidate compound would have limited potential for wide application to cash crop such as sweet peppers. Therefore, it is recommended that JP503 be used only in a site-specific manner such as applications to trap crops, barrier crops, or wild hosts adjacent to cash crop fields.

Keywords Bioassay - Biopesticide - Bumble bee $\cdot$ Green peach aphid $\cdot$ Sweetpotato whitefly $\cdot$ Western flower thrips

\section{Introduction}

In the Republic of Korea, sweet pepper (Capsicum апnиит L.), popularly known as paprika, was first grown in 1994 in Jeju Island and has since become a major export crop [1]. In addition to the importance of sweet pepper as an export crop, sweet pepper consumption in Korea has increased by over $40 \%$ in recent years [2]. In general, sweet peppers are commercially grown in greenhouse systems in Korea. In 2010, a nation-wide pest survey on sweet pepper was conducted for the first time in Korea, and the survey indicated that at least 15 pest species occurred in greenhouses and packing facilities [1]. Major pest complex found in greenhouse sweet pepper in Korea include Bemisia tabaci Gennadius (sweetpotato whitefly), Trialeurodes vaporariorum Westwood (greenhouse whitefly), Myzus persicae Sulzer (green peach aphid), and Tetranychus urticae Koch (two spotted spider mite) [1]. Interestingly, Kim et al. [1] found that the pest pressure on sweet pepper was generally lower in newer glasshouses compared to conventional plastic houses or open fields. However, 
there are very few studies examining life history or pest population dynamics on sweet pepper in Korea. In the case of whiteflies, a recent study monitored the spatiotemporal population dynamics of $B$. tabaci on sweet pepper in an experimental greenhouse and found that the pest populations aggregated near the greenhouse entrance and showed aggregated distributions [3].

In many crop systems, the use of synthetic insecticides has served as a main component in pest management strategies [4-6]. Currently, many sweet pepper growers in Korea rely largely on the use of synthetic insecticides to protect the crops against greenhouse pest complex. The intensive use of the insecticides and acaricides has led to a wide range of pest species in greenhouses developing resistance to the synthetic insecticidal chemicals [7-9].

Since insecticide resistance has been reported for the first time in $M$. persicae in 1955 [10], a number of serious problems caused by insecticide resistance have increased. Under the current circumstances, there is an urgent need for the development of alternative strategies to make pest management programs more sustainable [6]. The use of biopesticides can be a promising tool which can be incorporated into integrated pest management (IPM), hence reducing the amount of synthetic insecticide use. Although there is no formally agreed definition of a biopesticide, Chandler et al. [6] defined a biopesticide as "a mass-produced agent manufactured from a living microorganism or a natural product and sold for the control of plant pests." Using biopesticides as an IPM component can significantly reduce threat to human health and the environment because they have lower mammalian toxicity and faster degradation in the field [6]. However, repeated use of biopesticides can also result in pest populations developing resistance to the natural compounds. For instances, spinosad was widely used following its introduction in 1997, but resistance has already been reported from several important greenhouse pests such as western flower thrips [11]. Similarly, tetranychid mites have developed resistance to abamectin which is a macrocyclic lactone compound produced by Streptomyces avermitilis [12]. Therefore, it is critical to make continuous effort to utilize available chemicals more judiciously and continue to screen and develop new natural compounds as biopesticides.

In this study, we evaluated insecticidal effects of three natural compounds against three insect pests, B. tabaci, $M$. persicae, and $F$. occidentalis, in laboratory conditions. The three compounds were a plant extract, a commercial disinfectant solution, and a type of nitric oxide in aqueous solution. We selected one chemical as a candidate biopesticide based on the lethality to the three pests. Then, we examined whether the candidate material had adverse effects on a pollinator, Bombus terrestris (Hymenoptera: Apidae), which is most commonly used for pollination in sweet pepper greenhouses in Korea. We also evaluated whether the compound caused phytotoxicity on sweet pepper. Then, we conducted quantitative RT-PCR with a pest species (B. tabaci) and the pollinator (B. terrestris) to evaluate whether the candidate affected expression level of genes related to insect metabolisms. In addition to that, cell viability assays were also conducted to evaluate mammalian toxicity by the candidate material.

\section{Materials and methods}

\section{Insects}

Bemisia tabaci (Q-biotype) and Frankliniella occidentalis colonies were obtained from the National Institute of Agricultural Science, Republic of Korea, and the two colonies were maintained in laboratory. B. tabaci and F. occidentalis were reared on Nicotiana tabacum L. var. xanthi and Phaseolus vulgaris var. Humilis, respectively. The plants were watered every 2 days. Bombus terrestris and Myzus persicae colonies were purchased from Green AgroTech Inc. (Gyeongsan-si, Gyeongsangbuk-do, Republic of Korea) and Bio Utilization Institute (Andongsi, Gyeongsangbuk-do, Republic of Korea), respectively. The two species were used in the tests within 7 days after the purchase. All insects were maintained in a breeding room at under $26-28{ }^{\circ} \mathrm{C}, 40-50 \% \mathrm{RH}$, and $16 \mathrm{~L}$ : $8 \mathrm{D}$ photoperiod.

\section{Formulation of natural chemicals}

Three chemicals, named JP503, G.sol ${ }^{\circledR}$, and NO40, were tested to evaluate their potentials as biopesticides in this study. JP503 was a blend of JS408 and phytoncide oil: JS408 was extracted from Perilla frutescens var. crispa leaves, and detailed information on extraction method and formulation is presented in Kim et al. [3]; phytoncide essential oil was extracted from pine cone waste. Detailed information is provided in Kim and Lee [13]. Stock sample was formulated with $50 \mathrm{~g}$ of lecithin, $50 \mathrm{~g}$ of JS408, $3 \mathrm{~g}$ of phytoncide oil, $0.3 \mathrm{~g}$ of thymol, and $6.7 \mathrm{~g}$ of distilled water. Then, $10 \mathrm{~g}$ of the stock sample was diluted with $490 \mathrm{~g}$ of distilled water. NO40 was a type of nitric oxide in aqueous solution. To obtain NO40, undersurface water was inserted in steam generator with 300-mesh zeolite powder which was $3 \%$ of water capacity. Oxygen, hydrogen, and nitrogen gas were separated by two heated electrode bars in the generator and were pumped into activated carbon in a purification tank to filter nitrogen dioxide. Only nitric oxide steam was passed through the cooling chamber and condensed into liquid solution. For G.sol ${ }^{\circledR}$, silver colloid fluid was first obtained. This fluid is made with $\mathrm{AgNO}_{3} 10 \mathrm{~g}$, 
$99.5 \%$ ethanol $20 \mathrm{~g}$, and flavonoid $0.01 \mathrm{~g}$ using alcohol reduction method in $80{ }^{\circ} \mathrm{C}$ for $5 \mathrm{~h}$. Detailed manufacturing information was described in Kim et al. [14]. The average particle diameter was $20-50 \mathrm{~nm}$ and diluted with distilled water to a concentration of $500 \mathrm{ppm}$. Using $500 \mathrm{ppm}$ silver colloid fluid as solvent and TEOT (titaniumethoxyorthotitanate) $35 \mathrm{~g}$, hydrolysis and condensation reaction were carried out at room temperature; $\mathrm{HNO}_{3} 0.5 \mathrm{~g}$ was used as a catalyst for hydrolysis. Stirring for $4-8 \mathrm{~h}$, reaction temperature was $60-85{ }^{\circ} \mathrm{C}$, and titanium dioxide particles (average particle size $1-100 \mathrm{~nm}$ ) were synthesized at a concentration of $1-5 \mathrm{wt} \%$.

The three materials, JP503, NO40, and G.sol ${ }^{\circledR}$, were analyzed by gas chromatograph-mass spectroscopy (GC/ MS), ion chromatograph (IC), and inductively coupled plasma-atomic emission spectrometer (ICP-AES), respectively. JP503 was analyzed by GC/MS with the same method described in Kim et al. [3] (Table 1). NO40 was analyzed by IC using Metrohm 883 Basic IC Plus (Metrohm, Cat.No. 2.883.0020, Herisau, Swiss) and the operating condition is summarized in Table 2. The standard reagent used was IC-1 Solution A 6 component anion standard at 100 ppm (High-Purity Standards, Cat.No. IC-1, Charleston, SC, USA), and calibration was performed at $0.1,0.5,2$, and $5 \mathrm{mg} / \mathrm{kg}$. The major elements in $\mathrm{G}_{\text {.sol }}{ }^{\circledR}$ were analyzed by ICP-AES. The operating conditions are as listed in Table 3. Reagents of extra pure redistilled water were distilled through Milli-Q Plus system (Millipore, Billerica, MA, USA), and as a standard stock solution, Ti and $\mathrm{Ag}$ were used (SPC Science, Cat.No. 140-000-221 and 140-001-471, Baie-d'Urfé, QC, Canada). As a sample injector, concentric glass nebulizer (00472020, PerkinElmer Inc., Waltham, MA, USA) was used. All these three materials were produced and analyzed by Phylus Co. Ltd. (Danyang, Chungbuk, Republic of Korea).

\section{Lethality of test materials to insect pests}

Laboratory bioassays were conducted to estimate insecticidal effects on three test materials on B. tabaci, M. persicae, and $F$. occidentalis. General bioassay procedures were established and executed by following the methods described in Kim et al. [3]. Each insect was individually introduced on a leaf disk which was dipped into the test materials or water, and dried before the introduction of insect. This experiment was replicated 30 times. The survival rate of the test insects was analyzed and compared between the four treatments (three test materials and untreated control) using Kaplan-Meier survivorship analysis (JMP 12.0.1, SAS Institute Inc., Cary, NC, USA).

\section{Toxicity of a candidate biopesticide to a pollinator}

In this experiment, both lethal and sublethal impacts of a candidate biopesticide were evaluated with $B$. terrestris in laboratory conditions. JP503 was selected as a candidate biopesticide based on the results of lethality tests with insect pests (see Results). For lethality test, the survivorship of B. terrestris was evaluated in the bioassays with slightly modified experimental arenas from the methods described above. In this experiment, B. terrestris was placed in an insect breeding jar $(10 \times 4 \mathrm{~cm})$ (diameter $\times$ height $)$ (310102, SPL, Pocheon-si, Republic of Korea) with a wet 90 -mm-diameter filter paper on the bottom which was applied with the candidate biopesticide or water. The survivorship data were compared between the two treatments using Kaplan-Meier survivorship analysis (JMP 12.0.1, SAS Institute Inc., Cary, NC, USA). To evaluate sublethal impacts by the candidate material, a video-tracking system, EthoVision XT 10 (Noldus Information Technologies, Wageningen, The Netherlands) was used. The tracking system recorded the behaviors of $B$. terrestris for $6 \mathrm{~h}$ and analyzed the walking distance,
Table 1 Experimental conditions of gas chromatography/mass spectroscopy (GC/MS) to analyze JP503

\begin{tabular}{ll}
\hline Parameter & Condition \\
\hline Column & DB-5 MS (30 m length $\times 0.25 \mu \mathrm{m}$ thickness (Agilent)) \\
Mass & $40-600 \mathrm{amu}$ \\
Inlet Temp. & $310^{\circ} \mathrm{C}$ \\
Source Temp. & $320{ }^{\circ} \mathrm{C}$ \\
Injector Temp. & $280{ }^{\circ} \mathrm{C}$ \\
Oven Temp. & $50{ }^{\circ} \mathrm{C}$ (hold 3 min) $-2{ }^{\circ} \mathrm{C}$ per min to $150{ }^{\circ} \mathrm{C}-2{ }^{\circ} \mathrm{C}$ per min to $300{ }^{\circ} \mathrm{C}$ (hold $10 \mathrm{~min}$ ) \\
Flow Temp. & $\mathrm{He}$ gas, $1.5 \mathrm{~mL}$ per min \\
Spilt ratio & $10: 1$ \\
Injection Vol. & $1 \mu \mathrm{L}$
\end{tabular}

Inlet Temp. indicates the temperature of the portion connecting with GC and mass detector; Source Temp. indicates the ion source temperature of mass detector; Injector Temp. indicates the temperature of the portion for injecting sample to the detector part of the GC 
Table 2 Operating conditions of ion chromatograph (IC) to analyze NO40

\begin{tabular}{ll}
\hline Parameter & Condition \\
\hline Instrument & Ion chromatography Metrohm 883 Basic IC Plus \\
Column type & Metrosep A Supp5-150/4.0 \\
Eluent composition & Anion-3.2 $\mathrm{mM} \mathrm{Na}_{2} \mathrm{CO}_{3}+1.0 \mathrm{mM} \mathrm{NaHCO}_{3}$ \\
Channel & Conductivity \\
Injection volume & $100 \mu \mathrm{L}$ \\
Pressure & $9.12 \mathrm{MPa}$ \\
Flow rate & $0.700 \mathrm{~mL}$ per min \\
Recording time & $18.0 \mathrm{~min}$ \\
\hline
\end{tabular}

Table 3 Operating condition of inductively coupled chromatograph-mass spectroscopy (ICP-AES) to analyze G.sol ${ }^{\circledR}$

\begin{tabular}{ll}
\hline Parameter & Condition \\
\hline Model & Thermo scientific iCAP 7400 duo inductively coupled plasma-atomic emission spectrometer (ICP-AES) \\
Frequency & $27.12 \mathrm{MHz}$ \\
Power & $1350 \mathrm{~W}$ \\
Plasma gas flows & $12 \mathrm{~L} / \mathrm{min}$ \\
Auxiliary gas flows & $0.50 \mathrm{~L} / \mathrm{min}$ \\
Nebulizer gas flows & $0.50 \mathrm{~L} / \mathrm{min}$ \\
Sample uptake flows & $1.0 \mathrm{~mL} / \mathrm{min}$ \\
\hline
\end{tabular}

velocity, and angular velocity of bee's movement after being exposed to the candidate biopesticide or water for $4 \mathrm{~h}$. As a food source, B. terrestris was offered sugared water-soaked cotton. Experimental settings and analysis methods for the video tracking are described in detail in Lee et al. [15]. The behavioral parameters were compared between the two treatments using $t$ test (JMP 12.0.1, SAS Institute Inc., Cary, NC, USA).

\section{Phytotoxicity of a candidate biopesticide to sweet pepper}

Potential phytotoxicity of JP503 was evaluated in 14 days on sweet pepper leaves in greenhouse. In an experimental greenhouse, healthy and undamaged plants were randomly selected from 13-week-old sweet peppers (Capsicum annuum L. var. Scirocco). The selected plants were then randomly assigned to the biopesticide treatment or untreated control. The leaves were sprayed with the biopesticide or water, and they were collected from the plants at 2, 7, and 14 days after the spray. The collected leaves were subjected to blind tests in the laboratory to evaluate the level of phytotoxicity by five participants, following a guideline developed by National Institute of Agricultural Sciences, Korea [3]. The data were analyzed using $t$ test to compare the levels of phytotoxicity between the two treatments (JMP 12.0.1, SAS Institute Inc., Cary, NC, USA).

\section{Quantitative RT-PCR}

qRT-PCR was used to quantitatively measure a specific gene expression level. The selected genes were related to the synthesis of adenosine triphosphate (ATP) through oxidative phosphorylation at mitochondrial electron transport chain of B. tabaci and B. terrestris. To further determine whether the JP503 biopesticide affects the expression of genes involved in metabolism, B. tabaci and B. terrestris were treated with the JP503 biopesticide, and the relative levels of transcripts determined using qRT-PCR. Total RNA was isolated using the ZR Tissue \& Insect RNA MicroPrep $^{\mathrm{TM}}$ (R2030, Zymo Research, USA) and reverse transcribed into cDNA with the TOPscript ${ }^{\mathrm{TM}}$ cDNA Synthesis Kit (EZ005S, Enzynomics, Daejeon, Republic of Korea) in keeping with the manufacturer's guidelines. Real-time PCRs were carried out in a $20-\mu \mathrm{L}$ reaction volume containing 1X HOT FIREPol ${ }^{\circledR}$ EvaGreen $^{\circledR}$ qPCR mix Plus (08-24-00001, Solis BioDyne, Tartu, Estonia) with the following primers described in Table 4.

\section{Cell viability assay}

CellTiter-Glo luminescent cell viability assay (G7570, Promega, Madison, WI, USA) was used to quantitatively measure the levels of ATP in metabolically active and viable cells. The assay was performed according to specified manufacturer's instructions. 
Table 4 Primers used for qRTPCR

\begin{tabular}{lll}
\hline Insect & Primer & Sequence $\left(5^{\prime} \rightarrow 3^{\prime}\right)$ \\
\hline Bemisia tabaci & Cytochrome c oxidase subunit 1 & TTTCACTTCCCGTTCTTGCG \\
& & ACCCAGGCTACCAAATACTTCT \\
& ATP synthase Fo subunit-6 & CTGATTCGGCCTTGGTCTCT \\
Bombus terrestris & NADH dehydrogenase subunit-1 & CAAAGGCTTGGATAAAACAGACA \\
& & GTGGTAATGTCGTTCGGGTT \\
& Cytochrome b-c1 complex subunit 9-like & CGGGCCGAACTCTAGCAGCCACCTT \\
& & CCCTCATTCAGCCTGTCGAA \\
& ATP synthase subunit b, mitochondrial & ATGTACCACGTCCAAAGCGT \\
& & CCTGTTGCACCAGTTTAGGG \\
& Cytochrome b-c1 complex subunit 8 & TGGGAGGAAAGAGGTTTGGAG \\
& AGCCTCACGTATTCCAGCAA \\
\hline
\end{tabular}

\section{Results}

\section{Identification of compounds in test materials}

Ingredient compounds of the three test materials were analyzed by chemical analysis such as GC/MS, IC, and ICP-AES. The major compounds of JP503 were $\alpha$-pinene (49.38\%), $\beta$-pinene $(16.227 \%)$, and D-limonene $(24.11 \%)$ (Table 5). From IC results, NO40 was composed of relatively low amount of anions $\left(\mathrm{F}, \mathrm{Cl}, \mathrm{NO}_{3}\right.$, and $\mathrm{SO}_{4}$ compared with the control distilled water; the amount of anions ( $\mathrm{F}, \mathrm{Cl}, \mathrm{NO}_{3}$, and $\mathrm{SO}_{4}$ ) was decreased by 16, 62, 37, and $56 \%$, respectively (Table 6). As ICP-AES analysis results, $1 \mathrm{~kg} \mathrm{G} . \mathrm{sol}^{\circledR}{ }^{\circledR}$ contained $369 \mathrm{mg} / \mathrm{kg}$ of $\mathrm{Ag}$ and $6370 \mathrm{mg} / \mathrm{kg}$ of $\mathrm{Ti}$, respectively.

Table 5 The ingredient composition of JP503 analyzed using gas chromatograph-mass spectroscopy

\begin{tabular}{lc}
\hline Ingredient & Component (\%) \\
\hline$\alpha$-pinene & 49.38 \\
$\beta$-pinene & 16.23 \\
D-limonene & 24.11 \\
3-carene & 1.31 \\
Camphene & 1.41 \\
$\beta$-myrcene & 3.23 \\
Bicycle [4, 1, 0] hept-3-ene, 3, 7, 7-trimethyl & 3.18 \\
Caryophyllene & 0.53 \\
Myristicin & 0.27 \\
B-Caryophyllene & 0.12 \\
Trans, trans-a-farnesene & 0.13 \\
Sesguiterpene & 0.09 \\
Total & 100.00 \\
\hline
\end{tabular}

\section{Lethality of natural materials to insect pests}

The mortality of three insect pests and one pollinator over $24 \mathrm{~h}$ in the biopesticide treatments and untreated control is presented in Fig. 1. Based on Kaplan-Meier survivorship with log-rank test, the results of survival rate analysis indicated that there were significant differences among the treatments in three tested insects (B. tabaci, $\chi^{2}=144.2217$, $d f=3$, and $P<0.001 ; F$. occidentalis, $\chi^{2}=131.6202$, $d f=3$, and $P<0.001$; and $M$. persicae, $\chi^{2}=104.2437$, $d f=3$, and $P<0.001)$. JP503 resulted in $100 \%$ mortality in $3 \mathrm{~h}$ for all the three insects tested. It was noted that the mortality of three insect pests in the JP503 biopesticide treatment started to sharply increase within 15 min (personal observation), before eventually resulting in almost $100 \%$ mortality in an hour. It showed statistical difference between JP503 treated and untreated control in three tested insects $(P<0.001)$. In contrast, the other two candidate materials yielded slower and modest insecticidal effects on the insects tested. In particular, at the end of time point, there was no significant difference between the NO40 treated and the control in three tested insects; the same result showed in $\mathrm{G} \cdot$ sol $^{\circledR}(P>0.1)$.

\section{Toxicity of a natural material to a pollinator}

The mortality of adult $B$. terrestris over $48 \mathrm{~h}$ caused by JP408 and NO40 was significantly higher than that by G.sol $^{\circledR}$ or untreated control $\left(\chi^{2}=151.7350 ; d f=3\right.$; $P<0.001$ ) (Fig. 2). The JP503 biopesticide resulted in $100 \%$ mortality of $B$. terrestris in $1 \mathrm{~h}$. In the tests evaluating sublethal effects of the JP503 biopesticide on $B$. terrestris movement, there was no significant difference between the biopesticide treatment and control in walking distance, walking velocity $(P>0.05)$. However, there was a significant decrease by JP503 in the angular velocity compared to untreated control $(P=0.0270)$ (Table 7). 
Table 6 Changes in ingredient composition of NO40 compared to distilled water analyzed using ion chromatography

\begin{tabular}{lcllll}
\hline Peak number & Retention time $(\mathrm{min})$ & Area $(\mu \mathrm{S} / \mathrm{cm}) \times \min$ & Height $(\mu \mathrm{S} / \mathrm{cm})$ & Concentration $(\mathrm{ppm})$ & Component name \\
\hline (A) Control distilled water & & & & \\
1 & 3.24 & 0.1032 & 0.882 & 0.359 & $\mathrm{~F}$ \\
2 & 3.53 & 0.0302 & 0.160 & Invalid & Invalid \\
3 & 3.83 & 0.0112 & 0.079 & 0.506 & $\mathrm{Cl}$ \\
4 & 4.88 & 0.0940 & 0.705 & 0.288 & $\mathrm{NO}_{3}$ \\
5 & 8.63 & 0.0301 & 0.120 & 0.531 & $\mathrm{SO}_{4}$ \\
6 & 13.30 & 0.0810 & 0.237 & & $\mathrm{~F}$ \\
$(B)$ NO40 & & & & 0.058 & $\mathrm{Cl}$ \\
1 & 3.24 & 0.0046 & 0.038 & 0.315 & $\mathrm{NO}_{3}$ \\
2 & 4.88 & 0.0548 & 0.404 & 0.107 & $\mathrm{SO}_{4}$ \\
4
\end{tabular}

(A)

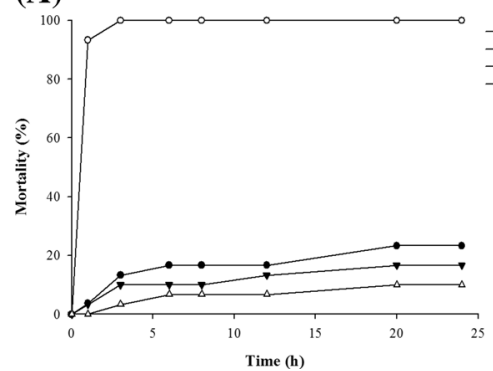

(B)

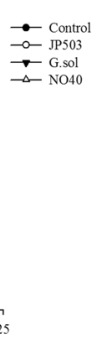

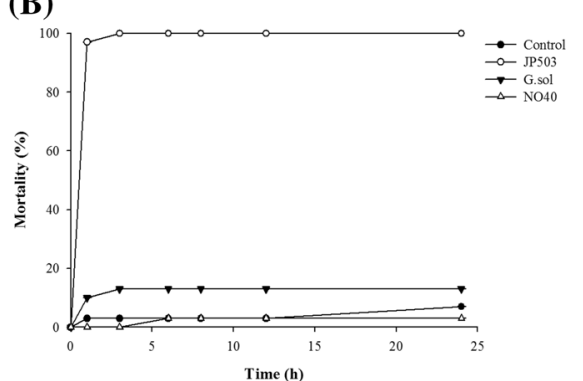

(C)

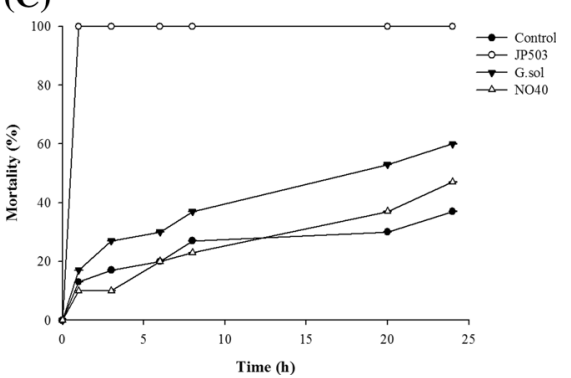

Fig. 1 Mortality of three insect pests (Bemisia tabaci (A), Frankliniella occidentalis (B), and Myzus persicae (C))

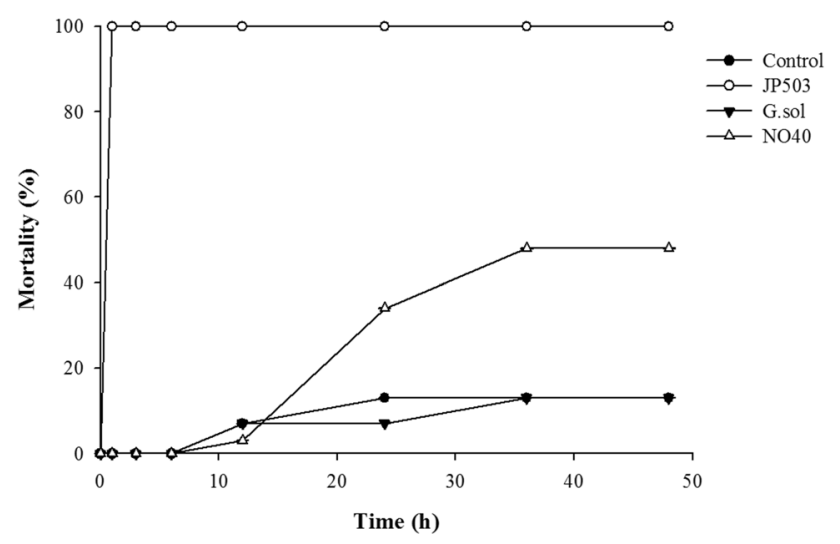

Fig. 2 Mortality of a pollinator, Bombus terrestris

\section{Phytotoxicity of a candidate biopesticide to sweet pepper}

The results of the phytotoxicity test indicate that the application of biopesticide caused significant damage on sweet pepper leaves. When the sweet pepper leaves were sprayed with JP503, the biopesticide formed a thin, transparent gel-like layer (Fig. 3A). Two days after the spray, the specks of spraying still remained. For this reason, at day 2, five participants scored 0.51 on average on the leaves treated with water but scored 1.11 on those treated with JP503 biopesticide $(P<0.001$, Fig. 4A) in the first blind test. Seven days after the spray, JP503-treated leaves had turned yellow and some of them had fallen, and the biopesticide spray mark had turned black and dead spots had formed on the sweet pepper leaves (Fig. 3B). In addition to that, it was noted that more leaves of JP503treated plants started falling more than those of untreated control (personal observation). And the participants gave higher phytotoxicity score on JP503-treated leaves than the untreated leaves $(P<0.001)$ (Fig. 4B). Fourteen days after the spray, the score of third blind test showed a similar trend to the previous results; the participants gave higher score on treated than untreated control $(P<0.001$, Fig. 4C). The treated leaves became yellow, more brown spots were formed compared to after day 7, and most of JP503-treated plant's leaves had fallen down (Fig. 3C, D). 
Table 7 Results of movement parameter of $B$. terrestris in sublethal conditions

\begin{tabular}{lcrrr}
\hline Parameter & \multicolumn{1}{c}{ Control } & \multicolumn{1}{c}{ JP503 } & \multicolumn{1}{c}{$t$ value } & $P$ value \\
\hline Walking distance \pm SE $(\mathrm{cm})$ & $68.37 \pm 10.39$ & $79.40 \pm 8.10$ & 0.8375 & 0.4076 \\
Walking velocity \pm SE $(\mathrm{cm} / \mathrm{s})$ & $0.28 \pm 0.04$ & $0.33 \pm 0.03$ & 0.8317 & 0.4108 \\
Angular velocity \pm SE (degree/s) & $86.20 \pm 5.36$ & $71.47 \pm 3.45$ & -2.3114 & 0.0270 \\
\hline
\end{tabular}

Angular velocity the change in direction of movement based on heading per unit time

(A) water (left) and JP503-treated (right) at day 2. (B) Leaf samples treated water (left) and JP503-treated (right) at day 7.

(C) Leaf samples treated water (left) and JP503-treated (right) at day 14. (D) A magnified image of phytotoxicity on JP503-treated sweet pepper leaf at day 14
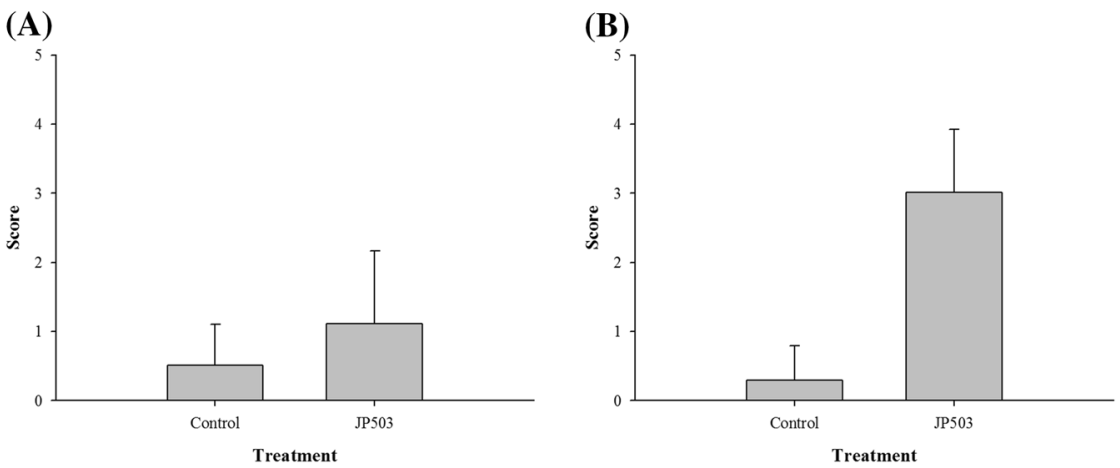
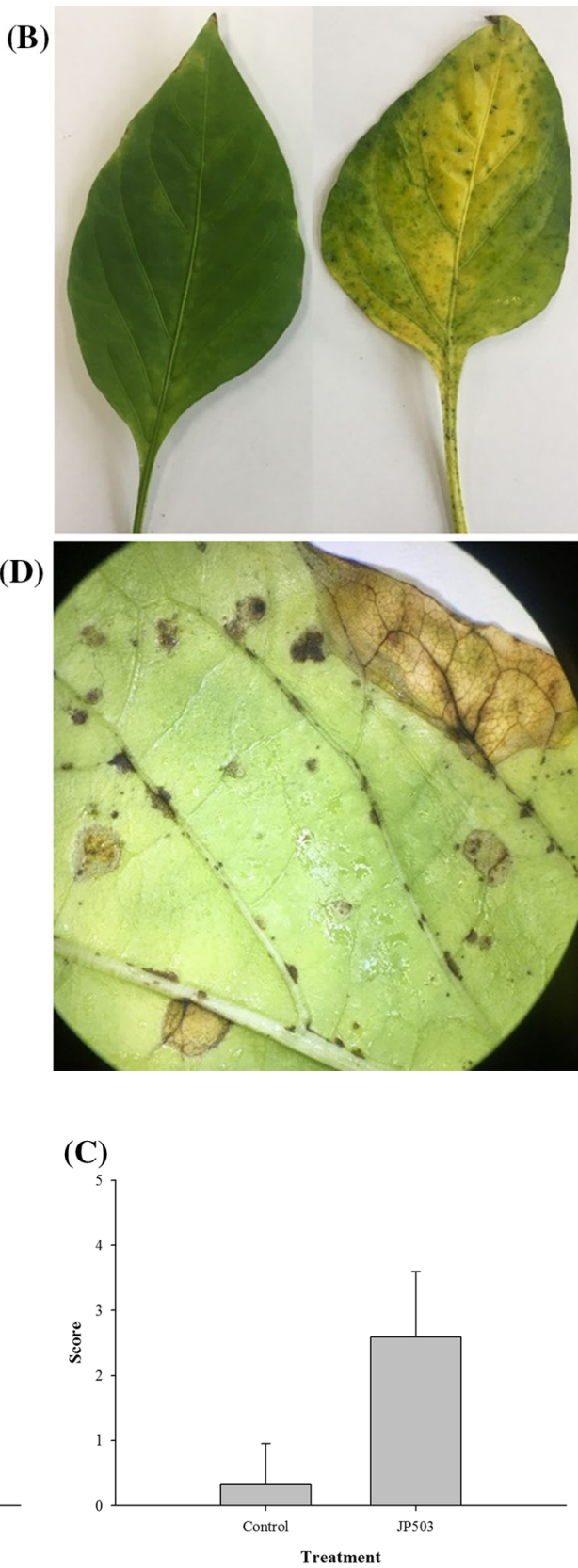

Fig. 4 Results of phototoxicity blind test for JP503 on sweet pepper leaves after spray 2 days (A), 7 days (B), and 14 days (C) (mean \pm SE) 
Effects of the JP503, candidate biopesticide, on an insect pest (B. tabaci) and a pollinator (B. terrestris)

For B. tabaci, at $5 \mathrm{~min}$ after treatment with the JP503 biopesticide, levels of cyclooxygenase $1(C O X-1)$ and ATP synthase Fo subunit-6 (ATP-6) transcripts in $B$. tabaci were reduced by approximately 50 and $66 \%$, respectively (Fig. 5A). For B. terrestris, treatment with the JP503 biopesticide for $5 \mathrm{~min}$ also significantly reduced the levels of NADH dehydrogenase 1 alpha subcomplex subunit 12 (NDUFA12), cytochrome b-c1 complex subunit 9-like (UQCR10-like), ATP synthase subunit b (ATP5F1), and cytochrome b-c1 complex subunit 8 (UQCRQ) by 83, 61, 58 , and $58 \%$, respectively (Fig. 5B). Thus, these data indicate that the JP503 biopesticide treatment down-regulates gene expression in both $B$. tabaci and B. terrestris.

\section{Cytotoxic effect of the biopesticide on mammalian cell lines}

To examine the cytotoxicity of the JP503 biopesticide on mammalian cell lines, murine macrophage cell line (RAW264.7), mouse embryonic fibroblast (MEF), and human foreskin fibroblast (HFF) were treated with various concentrations of the pesticide, and the amount of cellular ATP proportional to the number of metabolically active cells was analyzed using the CellTiter-Glo assay at 12, 24, and $48 \mathrm{~h}$ after treatment. Compared to the control, the JP503 biopesticide exhibited strong cytotoxic effect against mammalian cell lines at 1 and $10 \%$ within $12 \mathrm{~h}$ after

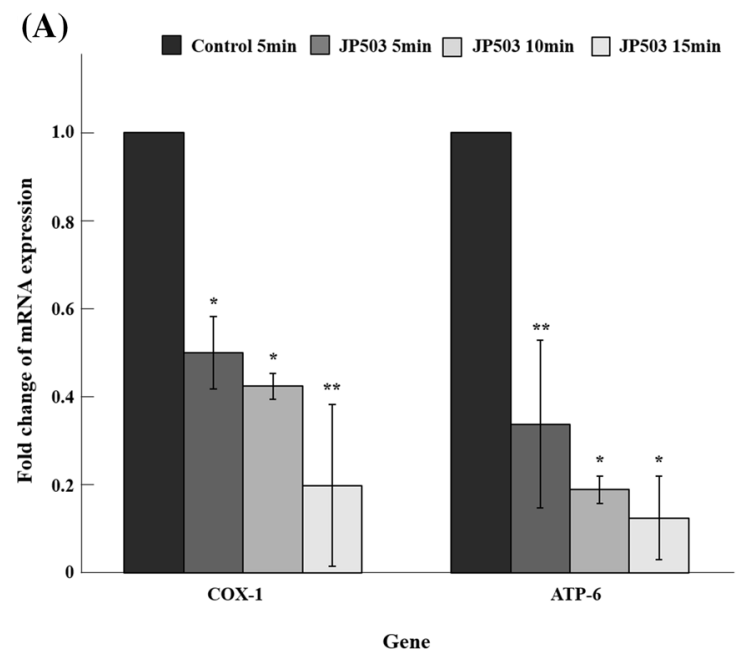

Fig. 5 The JP503 inhibits gene expression in B. tabaci and $B$. terrestris. (A) Groups of B. tabaci were treated with the JP503 for 5, 10 , and $15 \mathrm{~min}$, and the relative levels of COX-1 and ATP-6 transcripts were determined using qRT-PCR. Significant differences between samples were determined based on $P$ values obtained from the Student's $t$ test. *Significant at $P<0.05$ and **significant at treatment (Fig. 6). However, JP503 did not exhibit significant cytotoxic effects on mammalian cell lines at the concentration less than $0.1 \%$ (Fig. 6).

\section{Discussion}

Synthetic chemical pesticides have served as a main tool in crop protection over the past 50 years [6]. However, excessive and injudicious use of these synthetic pesticides has resulted in management failure and damage to human health and the environment [5-7, 9, 16, 17]. The use of pesticide products based on "old" chemistry is becoming more difficult and being withdrawn because of development of heritable resistance and new health and safety legislation [6].

Despite the urgent need for alternative tactics, the rate at which new and more environment-friendly chemicals such as biopesticides are being developed is very low [18]. For example, researches on bioactivity of plant derivatives to arthropod pests continue to expand, but only a handful of botanicals are currently used in crop protection [16]. To date, pyrethrum and neem are well established in the marketplace, and plant essential oil products have been recently added to the arsenal [16]. In a recent review article by Chandler et al. [6], only four biopesticides including Bacillus thuringiensis var kurstaki (bacterium), Beauveria bassiana (fungus), Cydia pomonella GV (virus), and azadirachtin (biochemical) were listed as active ingredients in the representative examples of commercially available biopesticides. Given that over 500 arthropod pest species

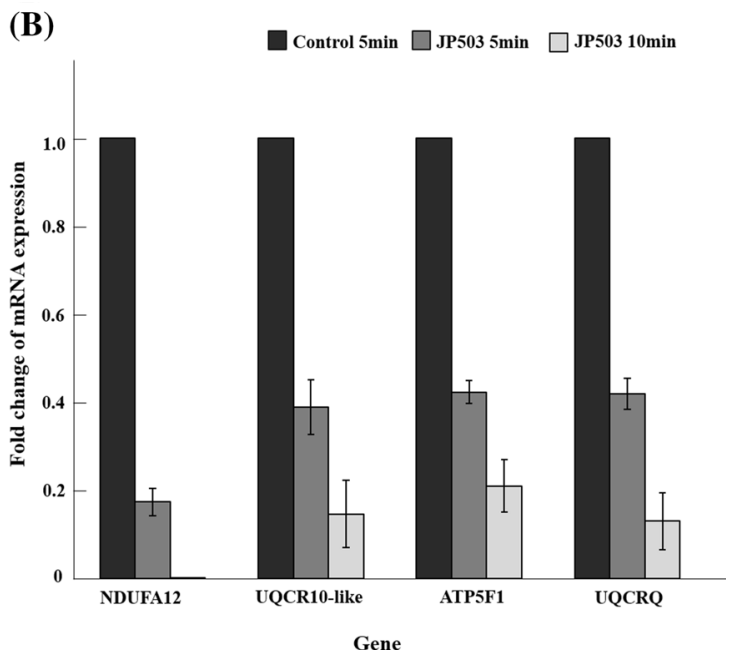

$P<0.1$. (B) Groups of B. terrestris were treated with the JP503 for 5 and $10 \mathrm{~min}$, and the relative levels of NDUFA12, UQCR10-like, ATP5F1 and UQCRQ transcripts were determined using qRT-PCR. Significant differences between samples were determined based on $P$ values obtained from the Student's $t$ test. All samples are significantly different at $P<0.05$ 

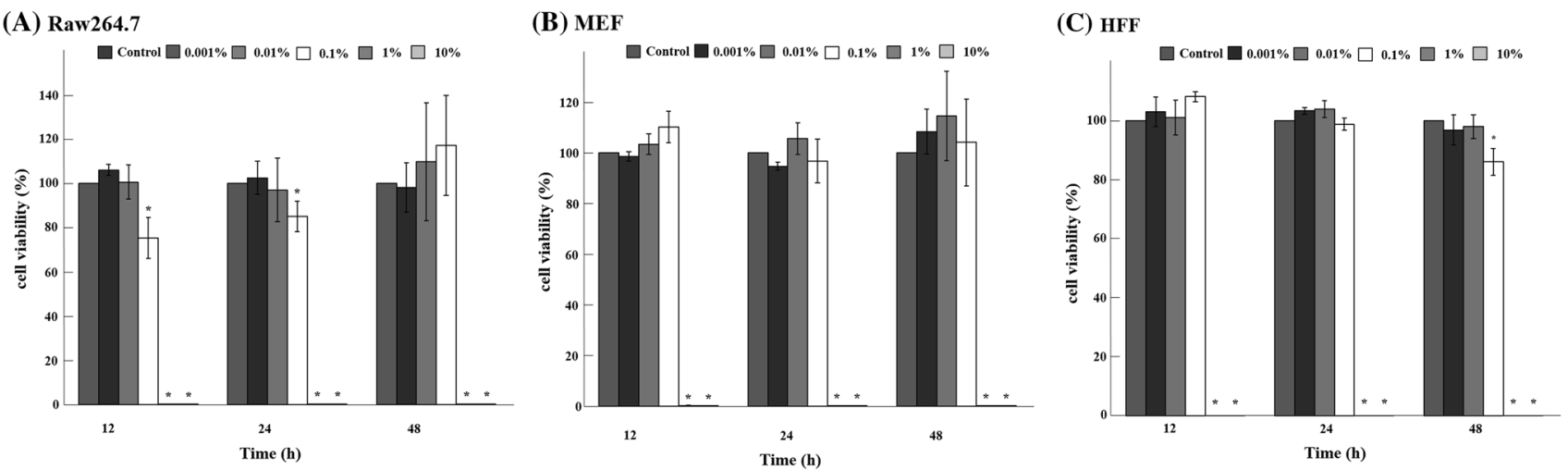

Fig. 6 Cytotoxic effects of the JP503 on mammalian cells. (A) Raw264.7, (B) MEF, and (C) HFF cells were treated with the JP503 at $0.001,0.01,0.1,1$, and $10 \%$. Control was untreated with JP503. At 12, 24, and $48 \mathrm{~h}$ after treatment, cell viability was analyzed

using the Cell Titer-Glo luminescent cell viability assay. Significant differences between samples were determined based on $P$ values obtained from the Student's $t$ test. *Significant at $P<0.05$

are known to have resistance to one or more pesticides, more research efforts must be put in place to develop and commercialize biopesticides as an alternative tactic to conventional synthetic chemicals [19].

The body of scientific literature addressing the effectiveness of synthetic pesticides for major greenhouse pests is fairly vast; however, research efforts to develop biopesticides against greenhouse pest complex that has emerged recently have been on the rise. For B. tabaci, previous studies indicate that pyrethrum, neem-based formulation, and essential oils have promising potentials to control whiteflies [20-22]. For T. vaporariorum, applications of pyrethrum resulted in fast and high mortality to the adults but also showed high toxicity on a whitefly parasitoid Encarsia formosa [23]. In the same study, the authors concluded that a commercial neem-based formulation had the most potential for use in an IPM program because the neem product caused $50 \%$ mortality of adult whiteflies in $6 \mathrm{~h}$ with very low toxicity to the parasitoid. Choi et al. [24] evaluated 53 plant essential oils for their insecticidal activities against $T$. vaporariorum and documented that 17 oils at the concentration of $2.3 \times 10^{-3} \mu \mathrm{L} / \mathrm{mL}$ caused more than $90 \%$ mortality in $24 \mathrm{~h}$. For $M$. persicae, four biorational insecticides (pyrethrins, neem extract, capsaicin extract, and insecticidal soap) were toxic to aphids. The combined use of these insecticides provided synergistic activity on aphid mortality in laboratory conditions [25]. In the same study, however, it was found that under field conditions that these insecticides failed to provide significant levels of control of the aphids. Interestingly, Lo et al. [26] reported that pyrethrum mixed with mineral oil was highly effective by reducing $M$. persicae population by over $75 \%$ in field conditions. Also, the insecticidal activity of Cinnamomum cassia and Coriandrum sativum oils showed that they could be an effective natural acaricide and insecticide [27]. For T. urticae, lethal toxicity of biopesticides (pyrethrins, azadirachtin, rotenone, and $B$. bassiana) was evaluated with $T$. urticae females and eggs. In general, females were more susceptible to the pesticides than eggs; the pesticides resulted in significant decrease in the female survival rates by $31-86 \%$ compared to untreated control in laboratory conditions [28]. In addition to that, Momen et al. [29] demonstrated that mint, Mentha virdis L., had significant repellency and lethal toxicity to $T$. urticae in laboratory conditions.

In this study, three materials were tested by laboratory bioassay, and only one material, JP503, showed acute and high insecticidal effect. JP503 is composed of $\alpha$-pinene, $\beta$ pinene, and D-limonene, which belong to monoterpene [30]. These three compounds have been reported to have antibacterial activities [31], anti-inflammatory, and anticancer potential [32]. In addition, $\alpha$-pinene and $\beta$-pinene were attributed to synergetic insecticidal effects when they were used with some essential oil compounds together $[33,34]$. Limonene is an active insecticidal compound in several pesticides used as insecticides, insect repellent, dog and cat repellents [35].

Although JP503 has great potential as a biopesticide causing acute and high lethality on the pest complex tested in this study, the impact of JP503 was also highly detrimental to a beneficial pollinator, B. terrestris. The mortality of JP503-treated bees was $100 \%$ within $1 \mathrm{~h}$, with apparent moribund conditions (e.g., paralyzing the body) before death. Unfortunately, this means that the current formulation of JP503 cannot fit into IPM programs for sweet pepper in which the use of pollinators plays a key role in the greenhouse. To avoid detrimental impacts of JP503 on the pollinator, it would be crucial to decouple time windows between insecticide applications and pollinator's release. Given that commercialized pollination systems using $B$. terrestris are easy to deploy and retrieve, this strategy is practical for growers. Currently, many 
growers use synthetic insecticides with the same strategy proposed above.

There is an expanding body of scientific literature addressing the impact of insecticides on pollinators [36-38]. Lethal effects of insecticides reduce directly the number of pollination service providers. For this reason, traditional measurement of side effects of insecticides to beneficial insects has largely been limited to the estimation of an acute median lethal dose or concentration [36]. In addition to direct mortality of the beneficial, however, sublethal impacts of insecticides on physiology and behavior of those insects must be considered for complete understanding the impact of insecticides [36]. In particular, pollinators used for greenhouse crops are more likely to be exposed to sublethal dose of insecticides, because they are typically released between insecticide applications. In this study, we found that in dry residue condition, JP503 did not cause significant changes in walking mobility of the pollinators.

Potential adverse effects of insecticides on plants have been studied with various synthetic and natural compounds [39-42]. Plant injuries from chemicals are called phytotoxicity [41]. In broad sense, chlorosis or yellowing of leaves, leaf distortion, and stunting of growth have been reported as examples of the impact of phytotoxicity [41]. Olofinboba and Kozlowski [39] found that systemic insecticides including acephate, chlorpyrifos, and oxamyl were variously toxic to Pinus halepensis seeds and seedlings. In particular, direct application of oxamyl to seed suppressed completely germination in the study. Isoalantolactone, a natural product isolated from Inula racemose, was found to have toxic activities against rice weevil ( $\mathrm{Si}$ tophilus oryzae); however, the product also had strong phytotoxic effects on seed germination and seedling growth of wheat [42]. Interestingly, this side effect was reduced substantially by shortening the treating time.

In this study, along with the detrimental effects of JP503 on $B$. terrestris, the observed phytotoxicity to sweet pepper significantly limits the use and commercialization of this material. The results of this study indicate that JP503 caused severe phytotoxicity such as gel-like layer when the leaves were dipped in laboratory, and black dead spots in field condition when they were sprayed. To alleviate this phytotoxicity issue, the formulation of JP503 must be modified in further studies by identifying the compounds in JP503 responsible for phytotoxicity. With the current formulation of JP503, the use of this biopesticide should be limited to wild host plants adjacent to sweet pepper greenhouse or utilized in site-specific applications such as trap or barrier crops.

JP503 significantly down-regulated expression levels of cytochrome c oxidase subunit 1 and ATP synthase Fo subunit-6 genes in $B$. tabaci and NADH dehydrogenase subunit-1, cytochrome b-c1 complex subunit 9-like, ATP synthase subunit $\mathrm{b}$ and cytochrome $\mathrm{b}-\mathrm{c} 1$ complex subunit 8 genes in $B$. terrestris. In addition, the viability of Raw264.7, MEF and HFF cells was drastically reduced by JP503 treatment. These data indicate that JP503 exerts significant cytotoxicity against arthropods as well as mammalian cells that may cause reduction in the global gene expression.

To reduce the use of synthetic insecticides and develop alternative strategies for pest management, we evaluated three materials as potential biopesticides in laboratory bioassays. In results, JP503 showed acute and high toxicity to the greenhouse pest complex tested in the laboratory bioassay condition. However, JP503 resulted extremely high mortality of pollinator and caused severe phytotoxicity on sweet pepper plants. Therefore, various formulations of JP503 need to be developed and tested with pest and beneficial insects.

Acknowledgments This work was supported by Korean Institute of Planning and Evaluation for Technology in Food, Agriculture, Forestry and Fisheries (IPET) through Export Promotion Technology Development Program, funded by Ministry of Agriculture, Food and Rural Affairs (MAFRA) (114152-3).

\section{References}

1. Kim GD, Lee S, Kang EH, Shin YG, Jeon JY, Heo NY, Lee HS (2013) The pests survey of paprika export complexes and packing house in Korea. Korean J Agric Sci 40(2):93-99

2. Jeong WJ, Lee JH, Kim HC, Bae JH (2009) Dry matter production, distribution and yield of sweet pepper grown under glasshouse and plastic greenhouse in Korea. J Bio-Environ Control 18(3):258-265

3. Kim S, Jung M, Song YJ, Kang SC, Kim B, Choi IJ, Lee DH (2017) Evaluating the potential of the extract of Perilla sp. as a natural insecticide for Bemisia tabaci (Hemiptera: Aleyrodidae) on sweet peppers. Entomol Res 47(3):208-216

4. Van Lenteren JC, Woets JV (1988) Biological and integrated pest control in greenhouses. Annu Rev Entomol 33(1):239-269

5. Lenteren JCV (2000) A greenhouse without pesticides: Fact or fantasy? Crop Prot 19(6):37

6. Chandler D, Bailey AS, Tatchell GM, Davidson G, Greaves J, Grant WP (2011) The development, regulation and use of biopesticides for integrated pest management. Phil Trans R Soc Lond B Biol Sci 366(1573):1987-1998

7. Palumbo JC, Horowitz AR, Prabhaker N (2001) Insecticidal control and resistance management for Bemisia tabaci. Crop Prot 20(9):739-765

8. Dewar AM, Van Emden HF, Harrington R (2007) Chemical control. In: CABI, pp 390-420

9. Leeuwen TV, Vontas J, Tsagkarakou A, Dermauw W, Tirry L (2010) Acaricide resistance mechanisms in the two-spotted spider mite Tetranychus urticae and other important Acari: a review. Insect Biochem Mol Biol 40(8):563-572

10. Feng R, Isman MB (1995) Selection for resistance to azadirachtin in the green peach aphid, Myzus persicae. Experientia 51(8):831-833 
11. Bielza P, Quinto V, Contreras J, Torné M, Martín A, Espinosa PJ (2007) Resistance to spinosad in the western flower thrips, Frankliniella occidentalis (Pergande), in greenhouses of southeastern Spain. Pest Manag Sci 63(7):682-687

12. Sato ME, Silva MZD, Raga A, Souza Filho MFD (2005) Abamectin resistance in Tetranychus urticae Koch (Acari: Tetranychidae): Selection, cross-resistance and stability of resistance. Neotrop Entomol 34(6):991-998

13. Kim BY, Lee CT (2015) Production of phytoncide from Korean pine cone waste by steam distillation. Appl Chem Eng 26(6):648-658

14. Kim J, Cho I, Kim I, Kim C, Heo NH, Suh S (2006) Manufacturing of anti-viral inorganic materials from colloidal silver and titanium oxide. Rev Roum Chim 51(11):1121-1129

15. Lee DH, Wright SE, Leskey TC (2013) Impact of insecticide residue exposure on the invasive pest, Halyomorpha halys (Hemiptera: Pentatomidae): analysis of adult mobility. J Econ Entomol 106(1):150-158

16. Pimentel D (2005) Environmental and economic costs of the application of pesticides primarily in the United States. Environ Dev Sustain 7(2):229-252

17. Isman MB (2006) Botanical insecticides, deterrents, and repellents in modern agriculture and an increasingly regulated world. Annu Rev Entomol 51:45-66

18. Thacker JR (2002) An introduction to arthropod pest control. Cambridge University Press, Cambridge

19. Hajek AE (2004) Natural enemies: an introduction to biological control. Cambridge University Press, Cambridge

20. Aslan I, Özbek H, Çalmaşur Ö, Şahin F (2004) Toxicity of essential oil vapours to two greenhouse pests, Tetranychus urticae Koch and Bemisia tabaci Genn. Ind Crops Prod 19(2):167-173

21. Lynn OM, Song WG, Shim JK, Kim JE, Lee KY (2010) Effects of azadirachtin and neem-based formulations for the control of sweetpotato whitefly and root-knot nematode. J Korean Soc Appl Biol Chem 53(5):598-604

22. Golmohammadi G, Hosseini-Gharalari A, Fassihi M, Arbabtafti R (2014) Efficacy of one botanical and three synthetic insecticides against silverleaf whitefly, Bemisia tabaci (Hem.: Aleyrodidae) on cucumber plants in the field. J Crop Prot 3(4):435-441

23. Simmonds MSJ, Manlove JD, Blaney WM, Khambay BPS (2002) Effects of selected botanical insecticides on the behaviour and mortality of the glasshouse whitefly Trialeurodes vaporariorum and the parasitoid Encarsia formosa. Entomol Exp Appl 102(1):39-47

24. Choi WI, Lee EH, Choi BR, Park HM, Ahn YJ (2003) Toxicity of plant essential oils to Trialeurodes vaporariorum (Homoptera: Aleyrodidae). J Econ Entomol 96(5):1479-1484

25. Edelson JV, Duthie J, Roberts W (2002) Toxicity of biorational insecticides: activity against the green peach aphid, Myzus persicae (Sulzer). Pest Manag Sci 58(3):255-260

26. Lo PL, Bradley SJ, Murrell VC (1999) Evaluation of organicallyacceptable pesticides against the green peach aphid (Myzus persicae). Proc N Z Plant Prot Conf 1999:75-79

27. Park BY, Lee MJ, Lee SK, Lee SB, Jeong IH, Park SK, Jeon YJ, Lee HS (2017) Insecticidal activity of coriander and cinnamon oils prepared by various methods against three species of agricultural pests (Myzus persicae, Teyranychus urticae and Plutella xylostella). J Appl Biol Chem 60(2):137-140

28. Duso C, Malagnini V, Pozzebon A, Castagnoli M, Liguori M, Simoni S (2008) Comparative toxicity of botanical and reducedrisk insecticides to Mediterranean populations of Tetranychus urticae and Phytoseiulus persimilis (Acari Tetranychidae, Phytoseiidae). Biol Control 47(1):16-21

29. Momen FM, Amer SAA, Refaat AM (2001) Influence of mint and peppermint on Tetranychus urticae and some predacious mites of the family Phytoseiidae (Acari: Tetranychidae: Phytoseiidae). Acta Phytopathol Entomol Hung 36(1-2):143-153

30. Lee SW, Park DG, Kim KY (2012) Characteristics of phytoncide production at the recreation forest in the Chungbuk area. J Environ Impact Asses 21(2):279-287

31. Oh HJ, Ahn HM, So KH, Kim SS, Yun PY, Jeon GL, Riu KZ (2007) Chemical and antimicrobial properties of essential oils from three coniferous trees Abies koreana, Cryptomeria japonica, and Torreya nucifera. J Appl Biol Chem 50(3):164-169

32. Salminen A, Lehtonen M, Suuronen T, Kaarniranta K, Huuskonen J (2008) Terpenoids: natural inhibitors of NF- $\kappa B$ signaling with anti-inflammatory and anticancer potential. Cell Mol Life Sci 65(19):2979-2999

33. Alzogaray RA, Lucia A, Zerba EN, Masuh HM (2011) Insecticidal activity of essential oils from eleven Eucalyptus spp. and two hybrids: lethal and sublethal effects of their major components on Blattella germanica. J Econ Entomol 104(2):595-600

34. Lamiri A, Lhaloui S, Benjilali B, Berrada M (2001) Insecticidal effects of essential oils against Hessian fly, Mayetiola destructor (Say). Field Crops Res 71(1):9-15

35. Hebeish A, Fouda MM, Hamdy IA, El-Sawy SM, Abdel-Mohdy FA (2008) Preparation of durable insect repellent cotton fabric: limonene as insecticide. Carbohydr Polym 74(2):268-273

36. Desneux N, Decourtye A, Delpuech JM (2007) The sublethal effects of pesticides on beneficial arthropods. Annu Rev Entomol 52:81-106

37. Brittain C, Potts SG (2011) The potential impacts of insecticides on the life-history traits of bees and the consequences for pollination. Basic Appl Ecol 12(4):321-331

38. Laycock I, Lenthall KM, Barratt AT, Cresswell JE (2012) Effects of imidacloprid, a neonicotinoid pesticide, on reproduction in worker bumble bees (Bombus terrestris). Ecotoxicology 21(7):1937-1945

39. Olofinboba MO, Kozlowski TT (1982) Effects of three systemic insecticides on seed germination and growth of Pinus halepensis seedlings. Plant Soil 64(2):255-258

40. Straw NA, Fielding NJ, Waters A (1996) Phytotoxicity of insecticides used to control aphids on Sitka spruce, Picea sitchensis (Bong.) Carr. Crop Prot 15(5):451-459

41. Ibrahim MA, Kainulainen P, Aflatuni A, Tiilikkala K, Holopainen JK (2001) Insecticidal, repellent, antimicrobial activity and phytotoxicity of essential oils: with special reference to limonene and its suitability for control of insect pests. Agric Food Sci Finl 10:243-259

42. Liu CH, Mishra AK, Tan RX, Tang C, Yang H, Shen YF (2006) Repellent and insecticidal activities of essential oils from Artemisia princeps and Cinnamomum camphora and their effect on seed germination of wheat and broad bean. Bioresour Technol 97(15):1969-1973 